\title{
Where Killers Meet-Permeabilization of the Outer Mitochondrial Membrane during Apoptosis
}

\author{
Tom Bender and Jean-Claude Martinou \\ Department of Cell Biology, University of Geneva, 1211 Geneva 4, Switzerland \\ Correspondence: jean-claude.martinou@unige.ch
}

\begin{abstract}
Although mitochondria are usually considered as supporters of life, they are also involved in cellular death. Mitochondrial outer membrane permeabilization (MOMP) is a crucial event during apoptosis because it causes the release of proapoptotic factors from the mitochondrial intermembrane space to the cytosol. MOMP is mainly controlled by the Bcl-2 family of proteins, which consists of both proapoptotic and antiapoptotic members. We discuss the current understanding of how activating and inhibitory interactions within this family lead to the activation and oligomerization of MOMP effectors Bax and Bak, which result in membrane permeabilization. The order of events leading to MOMP is then highlighted step by step, emphasizing recent discoveries regarding the formation of Bax/Bak pores on the outer mitochondrial membrane. Besides the Bcl-2 proteins, the mitochondrial organelle contributes to and possibly regulates MOMP, because mitochondrial resident proteins and membrane lipids are prominently involved in the process.
\end{abstract}

M itochondria are essential for the life of the cell. They produce most of the ATP via oxidative phosphorylation thanks to the respiratory chain that is embedded in the inner mitochondrial membrane. Consequently, mitochondrial dysfunction is implicated in the development of many human diseases, in particular, neurodegenerative disorders (Lin and Beal 2006). Mitochondria are also prominently involved in cell death, because they play a crucial role in many apoptotic responses. Apoptosis is a self-destruction program that is essential during the development of multicellular organisms. Its dysregulation has also been recognized as a main feature of many pathological conditions, especially cancer (Llambi and Green 2011).

The executioners of apoptosis are a family of cysteine proteases termed caspases that cleave a variety of cellular targets, resulting in morphological changes, degradation of genomic DNA, and, ultimately, phagocytic removal of the apoptotic cell (Taylor et al. 2008). Caspases are synthesized as inactive zymogens that become activated after regulated limited proteolysis. Two different pathways of apoptotic signaling that result in the activation of executioner caspases 3 and 7 can be distinguished. In the extrinsic pathway, binding of ligands such as FasL or

Editors: Douglas C. Wallace and Richard J. Youle

Additional Perspectives on Mitochondria available at www.cshperspectives.org

Copyright (C) 2013 Cold Spring Harbor Laboratory Press; all rights reserved; doi: 10.1101/cshperspect.a011106

Cite this article as Cold Spring Harb Perspect Biol 2013;5:a011106 
TNF $\alpha$ to a death receptor on the plasma membrane leads to the activation of initiator caspase 8 . Active caspase 8 propagates the signal by directly cleaving and thereby activating caspases 3 and 7 , which continue a proteolytic cascade ultimately leading to the removal of the cell.

The intrinsic pathway, on the other hand, is initiated upon exposure to a number of stress situations, including DNA damage. A subclass of the Bcl-2 protein family termed BH3-only proteins (see below) becomes activated after an internal stress stimulus and translocates to the outer mitochondrial membrane (OMM), where they orchestrate a process called mitochondrial outer membrane permeabilization (MOMP). As an outcome of this process, pores are formed in the OMM, membrane integrity is lost, and contents of the intermembrane space gain access to the cytosol. One of the molecules that is rapidly released to the cytosol is cytochrome $c$, which is normally a soluble electron carrier between respiratory complexes III and IV. Together with the proapoptotic cytosolic factor APAF1, cytochrome $c$ assembles into a caspaseactivating complex termed the "apoptosome." This complex subsequently activates caspase 9 , which is able to cleave caspases 3 and 7, proceeding with the same downstream cascade as in the extrinsic pathway. Other intermembrane space proteins also contribute to cell death after being released into the cytosol (e.g., SMAC/Diablo, which blocks the caspase inhibitor protein XIAP).

Remarkably, the two pathways are not completely independent. Cross talk between the extrinsic and intrinsic pathways exists because of caspase 8-dependent cleavage of the BH3-only protein Bid. Upon cleavage, Bid becomes activated, and the truncated version, tBid, translocates to the surface of mitochondria to induce MOMP. In so-called type II cells, this mitochondrial feedback loop is needed to induce apoptosis through the extrinsic pathway, because of the requirement of XIAP antagonism by SMAC.

The loss of OMM integrity caused by MOMP is usually considered the point of no return in the whole process, because cells are committed to die once MOMP is initiated. Therefore, this process represents a major check- point of apoptosis and must be tightly controlled to ensure that it is initiated at the right time and place. The main molecular players of MOMP belong to the $\mathrm{Bcl}-2$ protein family. Integration of proapoptotic and antiapoptotic signals by the network of $\mathrm{Bcl}-2$ proteins determines whether or not the OMM is permeabilized. In the following sections, we describe in detail the stimulatory and inhibitory proteinprotein interactions within this family, discussing various models of how the MOMP effectors, Bax and Bak, become activated. Furthermore, we focus on the actual event of membrane permeabilization, summarizing the current understanding of how pores are formed in the OMM by Bax and Bak oligomers.

\section{MITOCHONDRIA AS A PLATFORM FOR INTEGRATION OF APOPTOTIC SIGNALS}

\section{Models for Interaction between Bcl-2 Proteins}

The family of Bcl-2 proteins can be subdivided both on the basis of the number of Bcl-2 homology $(\mathrm{BH})$ domains they possess and on their proapoptotic or antiapoptotic function (Youle and Strasser 2008; Chipuk et al. 2010). Both the antiapoptotic Bcl-2-like proteins (Bcl-2, Bcl-XL, MCL-1, Bcl-w, A1) and proapoptotic members Bax and Bak share four short homologous regions of high conservation, termed BH1 to 4. A variety of other Bcl-2 proteins like Bid, Bim, Bad, Puma, Noxa, and others, belong to a third subgroup called the BH3-only proteins. As the name indicates, they contain the conserved $\mathrm{BH} 3$ region only and are, apart from that, very heterogeneous. BH3-only proteins, generally speaking, serve as sensors of intrinsic stimuli because in response to DNA damage or ER stress, specific members become activated by transcriptional induction (Puma and Noxa), posttranslational modification (Bad), or limited proteolysis (Bid). BH3-only proteins are thus proapoptotic and transmit the signal by translocating to the OMM, where they either activate Bax and Bak or inhibit the antiapoptotic family members. The subsequent step is the homooligomerization of activated Bax and Bak at the OMM. Because this oligomerization is essential 
for membrane permeabilization, Bax and Bak are often termed the "effectors" of MOMP. The essential role of Bax and Bak at the downstream end of the signaling cascade was shown in cells lacking both proteins, because those cells are resistant to MOMP following diverse apoptotic stimuli (Wei et al. 2001).

Proapoptotic effectors Bax and Bak and the antiapoptotic Bcl-2-like proteins share a similar structure, being small globular proteins that display a characteristic arrangement of seven amphipathic $\alpha$-helices surrounding the central hydrophobic helix 5 (Muchmore et al. 1996; Suzuki et al. 2000; Moldoveanu et al. 2006). Interactions between individual proteins commonly involve the $\mathrm{BH} 3$ region located in helix 2. This region is also present in the $\mathrm{BH} 3$-only proteins, which, except for Bid, are believed to be intrinsically unstructured in solution and do not share any common features with other Bcl-2 family proteins except for the $\mathrm{BH} 3$ region. In nonapoptotic cells, Bax is primarily a cytosolic protein, whereas Bak and most of its antiapoptotic relatives are already attached to the OMM via a carboxy-terminal tail anchor (Lindsay et al. 2011). The carboxy-terminal $\alpha$-helix 9 of Bax also serves as a tail anchor that is able to direct the protein to the OMM. However, the helix is sequestered in a hydrophobic groove on the surface of the same molecule, composed of the $\mathrm{BH} 1$ and 3 regions. The tail anchor is displaced from the groove upon activation, leading to a cytosol-to-mitochondria redistribution of the protein (Hsu et al. 1997; Eskes et al. 2000). Further structural rearrangements then cause oligomerization of Bax or Bak so that MOMP can proceed.

Several models have been discussed for the activation of MOMP effectors that involve protein-protein interaction between the subgroups of Bcl-2 proteins (Fig. 1). In the derepressor model, Bax and Bak are considered active by default but are kept in check by Bcl-XL or another antiapoptotic protein (Chen et al. 2005; Willis et al. 2005, 2007). Activation of the effectors, according to this model, is achieved if a BH3-only protein replaces Bax or Bak at the binding site on $\mathrm{Bcl}-\mathrm{XL}$ so that the active effector
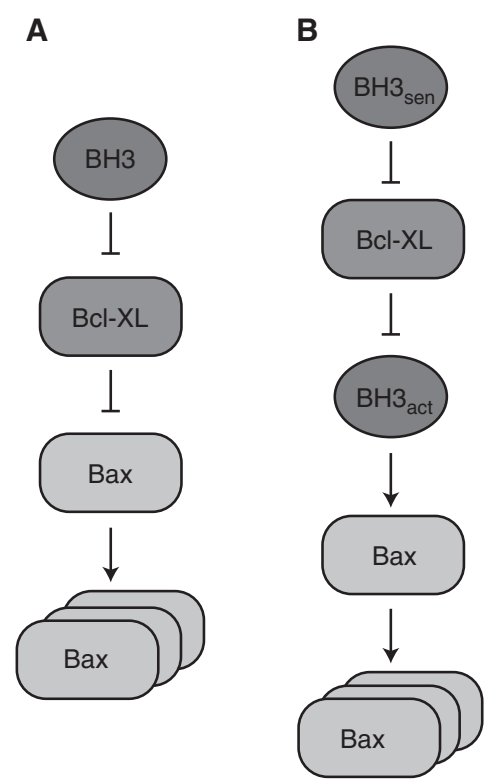

C

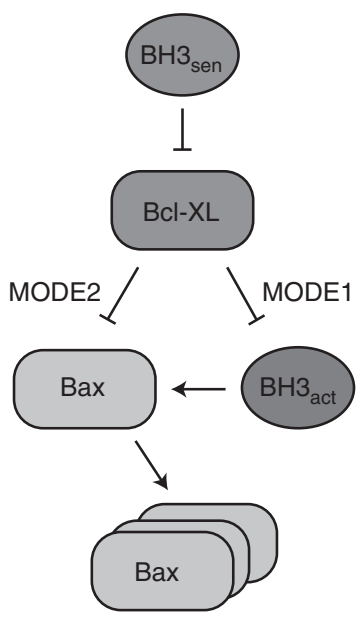

Figure 1. Models for activation of MOMP effectors. (A) Derepressor model. (B) Direct activator model. $(C)$ Current model, which is a refinement of the two former models. Antiapoptotic Bcl-2-like Bcl-XL proteins inhibit both direct activator BH3-proteins (MODE1) and effectors Bax and Bak (MODE2). Inhibition through $\mathrm{Bcl}-\mathrm{XL}$ is relieved by sensitizer $\mathrm{BH} 3$-only proteins. 
becomes liberated. The direct activator model, however, proposes that Bax and Bak must be activated by direct contact with a BH3-only protein (Desagher et al. 1999; Kuwana et al. 2002; Letai et al. 2002; Terradillos et al. 2002; Kim et al. 2006). This model postulates two classes of BH3-only proteins. "Direct activators" such as tBid and Bim are able to activate MOMP effectors unless they are sequestered by antiapoptotic $\mathrm{Bcl}-2$ proteins. To relieve this inhibition, "sensitizer" BH3-only proteins such as Bad or Noxa replace the direct activators by binding to Bcl-XL, so that Bax or Bak activation can occur. Indeed, by reconstituting membrane permeabilization in liposomes, direct activation of Bax by the BH3-only protein tBid could be shown (Kuwana et al. 2002; Lucken-Ardjomande et al. 2008b). Besides tBid, Bim and Puma have also been described as direct activators of Bax (Kuwana et al. 2005; Kim et al. 2006; Gallenne et al. 2009). Although the mode of action of Puma is more controversial and some investigators classify it as a sensitizer (Chipuk et al. 2008), the fact that a Bid/Bim/Puma triple knockout displays the same phenotype as a Bax/Bak double knockout strongly supports the notion of Puma being a direct activator (Ren et al. 2010).

Another model that has been proposed is termed "embedded together" because it emphasizes the role of the lipid bilayer in the interactions between proapoptotic and antiapoptotic Bcl-2 proteins (Leber et al. 2007, 2010). The model can be regarded as a refinement of the conflicting two former models because it integrates concepts from both (Fig. 1). In particular, antiapoptotic proteins are not seen as either inhibitors of activator $\mathrm{BH} 3$-only proteins (as in the "direct activator" model) or inhibitors of Bax and Bak (as in the "derepressor" model), but engage both. Like the "direct activator" model, the "embedded together" model differentiates between activator and sensitizer $\mathrm{BH} 3$ proteins. An elegant study using fluorescently labeled proteins in a reconstituted system in liposomes was able to establish a clear order of events during Bax activation (Lovell et al. 2008). Using FRET measurements between a variety of protein-attached fluorophores, different protein-protein interactions as well as membrane integration of proteins could be followed simultaneously and in real time. In this experimental setting, the first step is the targeting of tBid, the caspase 8-cleaved active form of Bid, to the membrane. Bax is subsequently recruited by tBid and integrates into the membrane, which can be inhibited by the addition of Bcl-XL. When Bax becomes activated at the membrane, the rate-limiting step is its oligomerization, which involves the recruitment and activation of more Bax molecules (Tan et al. 2006; Lovell et al. 2008). While Bax oligomerizes, liposome contents are released because of membrane permeabilization at the same time. By examining several Bax mutants, it could be confirmed that activation of Bax proceeds in a stepwise manner, and membrane targeting and oligomerization are separate events (Lucken-Ardjomande et al. 2008a; Kim et al. 2009). Interestingly, Bad could displace tBid from Bcl-XL, again confirming its role as a sensitizer (Lovell et al. 2008). Thus, both the initial recruitment of tBid and the activation of Bax require the presence of a membrane. We discuss the role of different membrane lipids in Bax activation below, including the controversial issue of whether or not cardiolipin is involved in this process.

The "embedded together" model not only proposes an important role for the mitochondrial outer membrane in the activation of Bax by direct activators Bid and Bim, but also for the recruitment of antiapoptotic Bcl-2 proteins. Just like Bax, its antiapoptotic opponent Bcl-2 undergoes extensive structural rearrangements when it becomes active at the OMM. These structural changes, which are required for inhibiting Bax oligomerization, appear to be initialized upon binding to activator $\mathrm{BH} 3$ proteins (Dlugosz et al. 2006). Furthermore, both Bax and $\mathrm{Bcl}-\mathrm{XL}$ were shown to be recruited to the membrane by tBid in a comparable way in another study (Billen et al. 2008). Based on these observations, it was proposed that $\mathrm{Bcl}-\mathrm{XL}$ acts as a dominant-negative version of Bax, providing an explanation for why two structurally similar proteins have opposing activities (Billen et al. 2008). Whereas Bax becomes activated by $\mathrm{tBid}, \mathrm{Bcl}-\mathrm{XL}$ remains associated with this activator, thus inhibiting its function. Likewise, 
Bax could interact with Bcl-XL as it would with another Bax molecule during oligomerization. However, in this case, Bax oligomerization would be prevented because no membrane-perforating higher-order structure can be formed by Bax/Bcl-XL heterodimers.

Further refinement to the "embedded together" model was made by a recent study that used an elegant domain-shuffling approach between homologous proteins to dissect the antiapoptotic proteins' binding to activator versus effector proteins (Llambi et al. 2011). Because tBid is inhibited by Bcl-XL, Bcl-2, and MCL-1 equally well, the investigators constructed chimeric proteins in which the $\mathrm{BH} 3$ domain of tBid was replaced by the $\mathrm{BH} 3$ domain of $\mathrm{Bax}$ or Bak. This yielded direct activator protein versions that could still activate both Bax and Bak, but which were inhibited only by a subset of the three antiapoptotic proteins. This allowed the investigators to distinguish inhibition of direct activators (termed MODE1) from inhibition of effectors (termed MODE2), showing that the latter mode of inhibition is more efficient. A scenario was proposed in which direct activators are under MODE1 inhibition at low stress levels, whereas MODE2 inhibition prevents the initiation of MOMP when the amount of direct activator rises. Under MODE2 inhibition, Bax was shown to be in an active conformation and tightly bound to mitochondria. This must be distinguished from the weaker association with mitochondria of unactivated Bax, as described in another recent study (Edlich et al. 2011). Cytosolic Bax is in a constant equilibrium with the loosely mitochondria-associated form in the presence of Bcl-XL because Bcl$\mathrm{XL}$ promotes its retrotranslocation back to the cytosol by a yet-undiscovered mechanism. However, even if a mutation in Bcl-XL prevents its interaction with $\mathrm{Bax}$ and Bax localizes to the OMM because of blocked retrotranslocation, MOMP is not readily caused (Edlich et al. 2011), presumably because of "MODE1" sequestration of direct activators (Llambi et al. 2011). Interestingly, in cancer cells, levels of $\mathrm{BH} 3$-only proteins are high, but inhibition by antiapoptotic Bcl-2 proteins still causes cell survival (Certo et al. 2006). This condition has been termed "primed to death," because BH3only levels in these cancer cells are constantly close to the threshold that would initiate apoptosis. Therefore, $\mathrm{BH} 3$-only mimetics like the drug ABT-737 provide an attractive tool to push "primed" cells over the limit in favor of apoptosis (Certo et al. 2006). Indeed, a recent study showed that the responsiveness of cancer cells to chemotherapeutic treatment correlates with "priming" by BH3-only levels (Ni Chonghaile et al. 2011).

\section{Structural Reorganization of Bax/Bak during Activation}

The discussed models of MOMP initiation agree that $\mathrm{BH} 3$-only proteins provide the death signal for tipping the balance between proapoptotic and antiapoptotic Bcl-2 family members. Reconstitution of the whole process in liposomes, using fluorescently labeled recombinant proteins, has established the order of events leading to the activation of effectors and, ultimately, membrane permeabilization, as described above. But what is the structural basis for the interactions taking place in vivo on the mitochondrial surface? Which structural rearrangements lead to the transition of inactive cytosolic Bax to the active killer in the OMM, and what triggers them?

As observed for complexes of antiapoptotic $\mathrm{Bcl}-2$ proteins with $\mathrm{BH} 3$ peptides derived from either activators or effectors, interactions involve the binding of a $\mathrm{BH} 3$ domain in the hydrophobic groove built from $\mathrm{BH} 1$ and $\mathrm{BH} 3$ (Sattler et al. 1997; Petros et al. 2000). The sequestration of a $\mathrm{BH} 3$ domain of a proapoptotic protein in the hydrophobic groove of an antiapoptotic inhibitor thus seems to be a common feature. However, it might also be assumed that all interactions between $\mathrm{Bcl}-2$ proteins involve the $\mathrm{BH} 3$ /groove contact, because the proapoptotic multidomain proteins also contain the groove structure on their surface. Interestingly, the hydrophobic groove of Bax in its cytosolic state is occupied by its own transmembrane helix, thereby preventing translocation to mitochondria. Therefore, in the case of Bax, the $\mathrm{BH} 3$ domain of an activator $\mathrm{BH} 3$-only protein would 
have to replace the transmembrane helix in the groove. However, it was shown that the stepwise activation of Bax by tBid leads to structural rearrangements at the amino terminus first (Kim et al. 2009). In the same study, it was proposed, based on the analysis of Bax mutants, that the displacement of helix 1 is required to release the tail-anchor helix 9. Hence, it is very likely that the first contact between an activating BH3 domain and Bax occurs at its amino-terminal region (Kim et al. 2009). This view is supported by the discovery of a binding region at helices 1 and 6 , using an $\alpha$-helical Bim-BH3-derived peptide stabilized by hydrocarbon stapling (Walensky et al. 2006; Gavathiotis et al. 2008). This novel interaction site is often termed the "rear pocket," because it is located on the opposite surface of Bax compared with the canonical $\mathrm{BH} 1 / \mathrm{BH} 3$ groove. Binding of the stapled Bim $\mathrm{BH} 3$ helix leads to the displacement of the loop between helices 1 and 2 (Gavathiotis et al. 2008). This rearrangement at the amino terminus of Bax has been recognized for a long time as a structural feature accompanying Bax activation (Hsu and Youle 1997). Subsequently, the amino-terminal rearrangements allow the tail-anchor helix 9 to pop out of the groove and to integrate into the OMM (Fig. 2) (Gavathiotis et al. 2008; Kim et al. 2009).
The BH3 domain of Bax is exposed as a consequence of the amino- and carboxy-terminal rearrangements triggered by $\mathrm{BH} 3$ binding to the rear pocket (Gavathiotis et al. 2010). On the basis of similarity in primary structures of the Bim and $\mathrm{Bax} \mathrm{BH} 3$ domains, it was proposed that the exposure of the $\mathrm{Bax} \mathrm{BH} 3$ domain could provide yet another device that is able to recruit and activate further Bax molecules. In that case, the exposed Bax BH3 domain would act just like the $\mathrm{BH} 3$ domain of a direct activator $\mathrm{BH} 3$-only protein. This would be consistent with the observation that a small number of $\mathrm{BH} 3$-only proteins can recruit a molar excess of Bax to the membrane through a Bax-autoactivating mechanism (Tan et al. 2006). Indeed, experimental evidence obtained with a stapled Bax BH3 peptide similar to the Bim peptide described above suggests self-propagating autoactivation of Bax (Gavathiotis et al. 2010). These results provide a very attractive model of Bax oligomerization. After initial activation of Bax through interaction with a $\mathrm{BH} 3$ domain at the rear pocket, not only is the membrane-anchor helix 9 released, but also the $\mathrm{BH} 3$ domain becomes exposed. By engaging another Bax molecule at its rear pocket, the activation could be propagated from molecule to molecule, leading to a higher-order structure of Bax molecules in a homo-oligomer

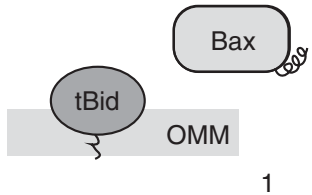

1

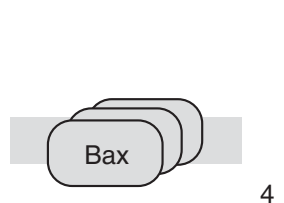

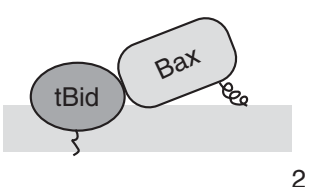

2
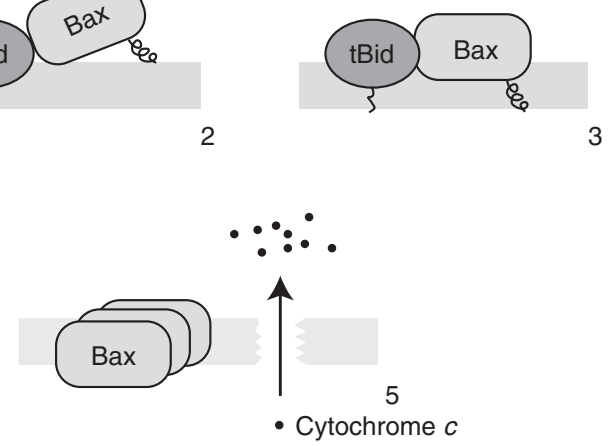

Figure 2. The order of events leading to MOMP. At first, an activator BH3 protein like tBid is targeted to the membrane (Step 1), which binds and recruits Bax to the membrane (Step 2). Upon activation, Bax exposes its carboxy-terminal membrane-anchor helix and becomes membrane integrated (Step 3). Activated Bax homooligomerizes (Step 4), which causes the formation of pores so that proapoptotic contents of the mitochondrial intermembrane space like cytochrome $c$ can be released (Step 5). 
at the OMM (Fig. 3A). Interestingly, if the release of helix 9 is blocked by mutation, the subsequent $\mathrm{BH} 3$ exposure does not lead to oligomerization (Gavathiotis et al. 2010), emphasizing that Bax must be targeted to the membrane in order to oligomerize.

In contrast to this asymmetric Bax oligomeric assembly, the formation of symmetric dimers has been suggested for Bak (Fig. 3B) (Dewson et al. 2008). The search for mutations in Bak that inhibit oligomer formation revealed that the $\mathrm{BH} 1$ and $\mathrm{BH} 3$ regions are prominently involved in this process. Moreover, cysteine residues were engineered in Bak, which were de- signed to match in a proposed reciprocal interaction of the $\mathrm{BH} 3$ domain of one monomer with the groove region of another. Because disulfide cross-linking stabilized Bak dimers, this is a strong indication of symmetric dimer formation. Finally, reciprocal mutations that allow noncovalent interactions between Bak monomers by the symmetric $\mathrm{BH} 3$ /groove contact could complement the loss-of-function mutations in oligomerization, pointing to a functional significance of this interaction (Dewson et al. 2008). This evidence is supported by another study aimed at determining the minimal requirements for Bax oligomerization, which

A

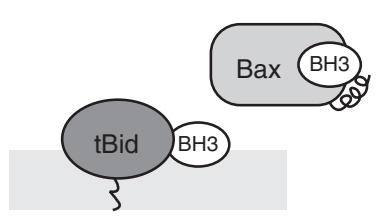

1

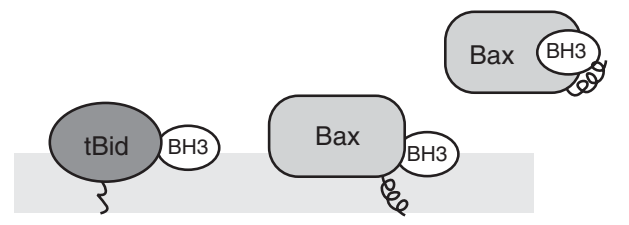

3

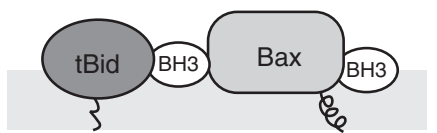

2

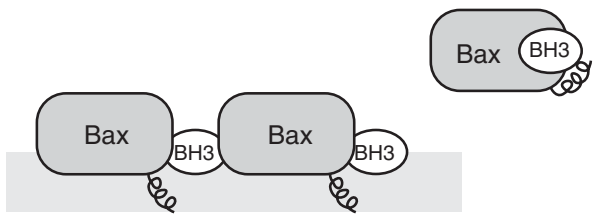

4

B
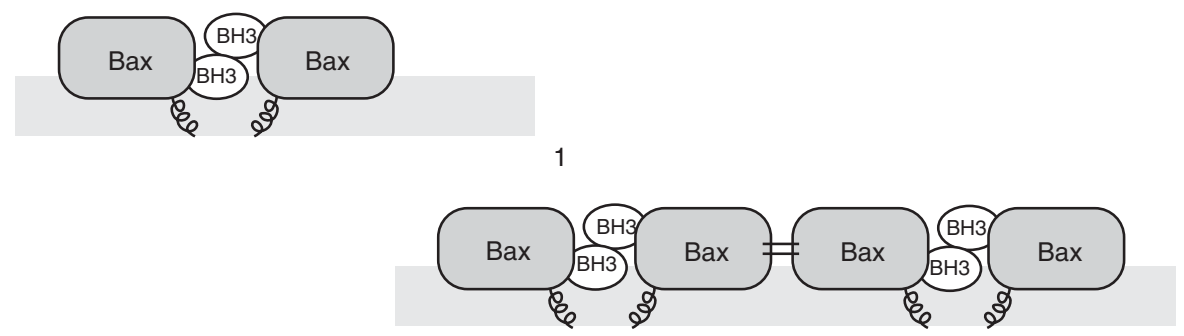

Figure 3. Bax activation and oligomerization. (A) Asymmetric autoactivation of Bax. Membrane-embedded tBid interacts through its BH3 domain with Bax at its rear pocket (Step 1). This results not only in the exposure of the Bax carboxy-terminal helix, but also in the exposure of the BH3 domain of Bax (Step 2). According to the asymmetric autoactivation model, the exposed BH3 domain of Bax can recruit further Bax molecules to the OMM (Step 3) and activate them (Step 4). (B) Symmetric dimer formation causes Bax oligomerization. Activated $\mathrm{Bax}$, which exposes its $\mathrm{BH} 3$ domain, forms symmetric dimers by a reciprocal interaction of one molecule's BH3 domain with the hydrophobic groove of another, and vice versa (Step 1). Bax dimers can then form higher-order oligomers through another symmetric interaction involving the $\alpha$-helices 6 at the surface opposite from the $\mathrm{BH} 3$-groove interaction (Step 2). 
found helices 2, 4, and 5 to be sufficient for this process (George et al. 2007). This region overlaps with the $\mathrm{BH} 1$ and $\mathrm{BH} 3$ domains found to be essential in symmetric dimer formation. Furthermore, several biochemical studies confirmed symmetric dimers involving the $\mathrm{BH} 3 /$ groove interaction for both Bax and Bak (Bleicken et al. 2010; Oh et al. 2010; Zhang et al. 2010). This potential interaction, however, would be reciprocal, resulting in both the $\mathrm{BH} 3$ domains and hydrophobic grooves of Bax being occupied. Therefore, to form higher-order oligomers, as observed during MOMP, dimers would need to be connected by yet another intermolecular contact. This additional contact is provided by another symmetric contact, because helix 6 of one Bax molecule was shown to interact with helix 6 of another (Dewson et al. 2009). Therefore, dimers formed by the $\mathrm{BH} 3 /$ groove contact could oligomerize by helix $6 /$ helix 6 interactions (Fig. 3B). A previously reported oligomerization mechanism via the coordination of zinc ions (Moldoveanu et al. 2006), on the other hand, could be ruled out (Dewson et al. 2009).

Thus, two conflicting views exist regarding Bax or Bak oligomer formation, based on the interaction of monomers in an either symmetric or asymmetric fashion. However, it is likely that neither model describes the mode of oligomerization exclusively. The symmetric model raises the question whether the $\mathrm{BH} 3$ exposure of one monomer, provoked by a direct activator, is sufficient to also activate the other monomer, or if this second monomer also has to be activated by a $\mathrm{BH} 3$-only direct activator binding to its rear pocket. The observation that $\mathrm{BH} 3$ ligands leave the rear pocket in a hit-andrun fashion and then seem to engage the effector at another site, possibly the $\mathrm{BH} 1 / \mathrm{BH} 3$ region (Kim et al. 2009), suggests that the initial interactions are highly dynamic. Thus, it is possible to envision a scenario in which the exposed $\mathrm{BH} 3$ domain of activated Bax can either activate other Bax molecules via the asymmetric rear-pocket activation site or interact with an already activated Bax molecule via the symmetric $\mathrm{BH} 3 /$ groove interface to initialize oligomerization.
Pore Formation by Bax/Bak Oligomers

The activation and oligomerization of proapoptotic Bcl-2 family effector proteins Bax and Bak are the prerequisites for MOMP. Although over the last few years models and concepts have emerged regarding the interactions between different Bcl-2 family members, as well as the structural rearrangements of Bax and Bak causing their oligomerization, the molecular connection between Bax or Bak oligomers and the actual event of membrane permeabilization is less evident (Fig. 1). Experiments with fluorescent dextrans of different sizes encapsulated by liposomes have shown that pores formed by activated Bax allow the release of molecules with a broad range of molecular mass from $10 \mathrm{kDa}$ to $2 \mathrm{MDa}$ (Kuwana et al. 2002). Although another study suggests that the maximum size of intermembrane space contents released in vivo is lower (Rehm et al. 2003), it is generally agreed that Bax pores accommodate the release of all proapoptotic intermembrane space (IMS) molecules like cytochrome $c$ or SMAC/Diablo.

So what is the mode of pore formation by oligomerized Bax? Bax alone is able to form pores in artificial planar lipid membranes (Antonsson et al. 1997; Schlesinger et al. 1997), although the experimental setup used in these experiments is differing substantially from the in vivo situation. The structural similarities of multidomain $\mathrm{Bcl}-2$ proteins like Bax or Bcl-XL to bacterial pore-forming toxins like colicins, in particular, the arrangement of amphipathic helices surrounding a central hydrophobic helix, suggest that Bax itself is able to porate membranes (Muchmore et al. 1996). Indeed, following activation, helices 5 and 6 of Bax were shown to insert into the membrane (Annis et al. 2005), emphasizing that these central helices might play an important role in membrane permeabilization. Moreover, replacement of helix 5 of Bcl-XL by the respective Bax helix enabled pore formation by the chimeric protein, thereby turning Bcl-XL into a killer molecule (George et al. 2007). This supports the notion that Bax oligomers are forming a proteinaceous channel in the OMM. Patch-clamp measurements of pores formed by Bak have led to the description 
of a channel structure termed the mitochondrial apoptosis-induced channel (MAC) by Martinez-Caballero et al. (2009). This channel shows an increase in conductance over time, being consistent with the stepwise incorporation of activated Bax homodimers into an oligomeric Bax pore. Alternatively, Bax oligomers could provoke the opening of a preexisting mitochondrial pore structure like the permeability-transition pore. However, this was effectively ruled out by experiments in cells lacking the central components of this pore structure (Baines et al. 2005; Nakagawa et al. 2005). Likewise, an involvement of the voltage-dependent anion channel (VDAC) was ruled out (Baines et al. 2007), although Bak was shown to interact with VDAC at the OMM, VDAC having an inhibitory function on Bak (Cheng et al. 2003).

Apart from observations in favor of a proteinaceous channel formed directly by a complex of activated Bax or Bak subunits, evidence also exists that a lipidic pore is formed. In a scenario like this, Bax or Bak could act like another bacterial toxin called melittin, which induces the formation of inverted micelle structures in membranes, resulting in lipidic pores. This view is supported by observations that pore formation is facilitated by the incorporation of lipids into the membrane that induce positive membrane curvature (Basanez et al. 2002). Remarkably, the pores formed by isolated Bax helix 5 were shown to be lipidic in nature (GarciaSaez et al. 2007; Qian et al. 2008), although, of course, a single helix might have different effects from full-length Bax. The analysis of pores formed by activated Bax in liposomes by cryoelectron microscopy, on the other hand, revealed that the pore edges are devoid of proteinaceous particles, thus strongly supporting the lipidic pore model (Schafer et al. 2009). Furthermore, a recent structural study using small-angle neutron scattering revealed that activated Bax in liposomes adopts a shape reminiscent of bacterial toxins known to form lipidic pores (Satsoura et al. 2012).

Yet another intriguing possibility for the mode of action of Bax oligomers was recently proposed by Montessuit et al. (2010). The researchers observed that the mitochondrial fis- sion factor Drp-1 facilitates pore formation by Bax in liposomes. Interestingly, a direct interaction of Bax and Drp-1 was not responsible for this effect, but the shape of the membrane played a key role. In particular, the existence of hemifusion intermediates promotes Bax oligomerization in this study (Montessuit et al. 2010). This type of intermediate is formed transiently during both the mitochondrial fusion or fission process and is characterized by an interconnected stalk between the outer leaflets of the two lipid bilayers, whereas the inner leaflets remain intact (Chernomordik and Kozlov 2008). Complete separation of the membranes or the formation of a fusion pore then completes membrane fission or fusion, respectively. Although Drp1 has so far only been described as a fission factor, it seems that it can also support vesicle fusion to the intermediate stage under the experimental conditions used (Montessuit et al. 2010). Interestingly, intermediate structures common to membrane fusion or fission have been described to be transiently leaky. Moreover, any perturbations in the fusion process in general can lead to permanent membrane leakage and thus the loss of membrane integrity (Engel and Walter 2008). It is thus conceivable that transient leakage also occurs during mitochondrial fission. Because mitochondria commonly fragment during apoptosis, Bax oligomers might take advantage of membrane vulnerability, insert into fragile sections at or near hemifission intermediates, and cause further perturbation during the fission process, leading to a loss of mitochondrial integrity (Martinou and Youle 2011). Consistent with this model, Bax has formerly been shown to insert at constriction sites, where it colocalizes with components of both the fusion and fission machineries (Karbowski et al. 2002).

The important role of membrane properties, especially membrane shape, not only in the recruitment of $\mathrm{Bcl}-2$ proteins to the OMM but also in pore formation itself, raises the question as to whether specific membrane lipids influence the course or the outcome of MOMP. The role of cardiolipin, a lipid restricted to mitochondrial membranes, has been controversially discussed in the literature. Several studies show that cardiolipin is required for $\mathrm{tBid} / \mathrm{Bax}$ - 
induced permeabilization of liposomes (Kuwana et al. 2002; Terrones et al. 2004; LuckenArdjomande et al. 2008b). The targeting of tBid, in particular, seems to require an interaction with this membrane lipid (Lutter et al. 2000). It remains questionable, however, if cardiolipin is required for MOMP in vivo, because it is primarily found in the inner mitochondrial membrane and its concentration in the outer membrane is low. One possible explanation for this obvious discrepancy is that cardiolipin is enriched in contact sites between the outer and inner membrane (Lutter et al. 2001), in such a way that local concentrations could be high enough to promote Bax activation. Other investigators have suggested that in vivo outer membrane proteins can take over the role that cardiolipin has in liposomes (Schafer et al. 2009). Candidate proteins include components of the TOM receptor complex, components of the fusion or fission machineries, or the mitochondrial carrier homolog MCTH2/MIMP (Ott et al. 2009; Zaltsman et al. 2010).

An additional study introduced yet another possibility for the requirement of membrane lipids in MOMP. Chipuk et al. (2012) discovered that contaminants originating from the endoplasmic reticulum, which are usually present in the mitochondrial preparations used for in vitro experiments, contain an MOMP-promoting factor. By stepwise purification of this factor from the contaminating microsomal fraction, a neutral sphingomyelinase was identified that promoted membrane permeabilization by tBid and Bak or Bax. Further investigation of the sphingolipid metabolism then revealed that Bak and Bax interact in the membrane with the sphingolipid metabolites sphigosin-1-phosphate and hexadecenal, respectively (Chipuk et al. 2012). Interestingly, this interaction resulted in the exposure of the 6A7 epitope in Bax, indicating activating structural rearrangements (see above). One might thus speculate that interaction of MOMP effectors with specific lipid components cooperates with direct activator $\mathrm{BH} 3$-only proteins by lowering the activation energy for the required structural remodeling. Furthermore, the researchers showed that cardiolipin is not needed for Bax activation in lipo- somes if the respective sphingolipid metabolite, hexadecenal, is present (Chipuk et al. 2012). All of these observations give rise to a potentially important role of the contact between mitochondria and the endoplasmic reticulum during apoptosis.

\section{CONCLUDING REMARKS}

Besides hosting numerous essential metabolic pathways, mitochondria are also prominently involved in cell death. In vertebrate cells, death signals arising from internal stress-sensing pathways converge on the outer mitochondrial membrane, where the effector $\mathrm{Bcl}-2$ proteins Bax and Bak become activated, integrate into the membrane, homo-oligomerize, and thereby cause the loss of membrane integrity. The participation in the execution of apoptosis is just one example of how mitochondria are part of an interconnected cellular network that not only maintains life but also determines a cell's fate in a variety of situations. In this respect, it is not surprising that, besides dysregulation of cellular proliferation, the inhibition of cell death through apoptosis is also a common feature in the development of cancer (for review, see Llambi and Green 2011). Still, because regulation involves the interplay of proapoptotic and antiapoptotic Bcl-2 family proteins, apoptosis is not completely abolished in cancer cells. On the contrary, cancer cells have been described as "primed" for death, because a high level of BH3-only proteins is counteracted by up-regulated antiapoptotic Bcl-2-like proteins. BH3-only mimetics like ABT-737 represent tools for tipping the balance in favor of death, thereby providing a promising possibility for therapeutic intervention (Vogler et al. 2009).

However, although our knowledge of the early steps of MOMP (i.e., Bax targeting, activation, and oligomerization) has expanded substantially over the past few years, the actual event of membrane permeabilization by Bax or Bak oligomers remains, in part, mysterious. It has become evident that the outer membrane of mitochondria itself is not only providing the grounds for MOMP, but actively participates in this process. Membrane lipids and also resident 
mitochondrial proteins seem to be involved in all of the steps leading to MOMP, from the recruitment of $\mathrm{tBid}$ or other direct activators to the pore formation itself. Like cytochrome $c$, which normally serves as an electron carrier between respiratory complexes, other mitochondrial proteins are likely to have dual functions both in mitochondrial biology and apoptosis. On the other hand, there is growing evidence that $\mathrm{Bcl}-2$ proteins also participate in other cellular processes besides apoptosis, like the regulation of mitochondrial fusion and fission (Martinou and Youle 2011). Therefore, it is most likely that we are awaiting many more exciting discoveries regarding the role of mitochondria in cell death in the near future.

\section{ACKNOWLEDGMENTS}

We thank Dr. C. Rodley for critical reading of the manuscript and all members of the laboratory for their support. Work in our laboratory is supported by subsidy 31003A-141068/1 of the Swiss National Foundation. T.B. receives a fellowship from the Deutsche Forschungsgemeinschaft (BE 5103/1-1).

\section{REFERENCES}

Annis MG, Soucie EL, Dlugosz PJ, Cruz-Aguado JA, Penn LZ, Leber B, Andrews DW. 2005. Bax forms multispanning monomers that oligomerize to permeabilize membranes during apoptosis. EMBO J 24: 2096-2103.

Antonsson B, Conti F, Ciavatta A, Montessuit S, Lewis S, Martinou I, Bernasconi L, Bernard A, Mermod JJ, Mazzei G, et al. 1997. Inhibition of Bax channel-forming activity by Bcl-2. Science 277: $370-372$.

Baines CP, Kaiser RA, Purcell NH, Blair NS, Osinska H, Hambleton MA, Brunskill EW, Sayen MR, Gottlieb RA, Dorn GW, et al. 2005. Loss of cyclophilin D reveals a critical role for mitochondrial permeability transition in cell death. Nature 434: 658-662.

Baines CP, Kaiser RA, Sheiko T, Craigen WJ, Molkentin JD. 2007. Voltage-dependent anion channels are dispensable for mitochondrial-dependent cell death. Nat Cell Biol 9: 550-555.

Basanez G, Sharpe JC, Galanis J, Brandt TB, Hardwick JM, Zimmerberg J. 2002. Bax-type apoptotic proteins porate pure lipid bilayers through a mechanism sensitive to intrinsic monolayer curvature. J Biol Chem 277: $49360-$ 49365.

Billen LP, Kokoski CL, Lovell JF, Leber B, Andrews DW. 2008. Bcl-XL inhibits membrane permeabilization by competing with Bax. PLoS Biol 6: e147.
Bleicken S, Classen M, Padmavathi PV, Ishikawa T, Zeth K, Steinhoff HJ, Bordignon E. 2010. Molecular details of Bax activation, oligomerization, and membrane insertion. J Biol Chem 285: 6636-6647.

Certo M, Del Gaizo Moore V, Nishino M, Wei G, Korsmeyer S, Armstrong SA, Letai A. 2006. Mitochondria primed by death signals determine cellular addiction to antiapoptotic BCL-2 family members. Cancer Cell 9: 351-365.

Chen L, Willis SN, Wei A, Smith BJ, Fletcher JI, Hinds MG, Colman PM, Day CL, Adams JM, Huang DC. 2005. Differential targeting of prosurvival $\mathrm{Bcl}-2$ proteins by their $\mathrm{BH} 3$-only ligands allows complementary apoptotic function. Mol Cell 17: 393-403.

Cheng EH, Sheiko TV, Fisher JK, Craigen WJ, Korsmeyer SJ. 2003. VDAC2 inhibits BAK activation and mitochondrial apoptosis. Science 301: 513-517.

Chernomordik LV, Kozlov MM. 2008. Mechanics of membrane fusion. Nat Struct Mol Biol 15: 675-683.

Chipuk JE, Fisher JC, Dillon CP, Kriwacki RW, Kuwana T, Green DR. 2008. Mechanism of apoptosis induction by inhibition of the anti-apoptotic BCL-2 proteins. Proc Natl Acad Sci 105: 20327-20332.

Chipuk JE, Moldoveanu T, Llambi F, Parsons MJ, Green DR. 2010. The BCL-2 family reunion. Mol Cell 37: 299-310.

Chipuk JE, McStay GP, Bharti A, Kuwana T, Clarke CJ, Siskind LJ, Obeid LM, Green DR. 2012. Sphingolipid metabolism cooperates with BAK and BAX to promote the mitochondrial pathway of apoptosis. Cell 148: 9881000.

Desagher S, Osen-Sand A, Nichols A, Eskes R, Montessuit S, Lauper S, Maundrell K, Antonsson B, Martinou JC. 1999. Bid-induced conformational change of Bax is responsible for mitochondrial cytochrome $c$ release during apoptosis. J Cell Biol 144: 891-901.

Dewson G, Kratina T, Sim HW, Puthalakath H, Adams JM, Colman PM, Kluck RM. 2008. To trigger apoptosis, Bak exposes its $\mathrm{BH} 3$ domain and homodimerizes via $\mathrm{BH} 3$ : groove interactions. Mol Cell 30: 369-380.

Dewson G, Kratina T, Czabotar P, Day CL, Adams JM, Kluck RM. 2009. Bak activation for apoptosis involves oligomerization of dimers via their $\alpha 6$ helices. Mol Cell 36: $696-703$.

Dlugosz PJ, Billen LP, Annis MG, Zhu W, Zhang Z, Lin J, Leber B, Andrews DW. 2006. Bcl-2 changes conformation to inhibit Bax oligomerization. EMBO J 25: 2287-2296.

Edlich F, Banerjee S, Suzuki M, Cleland MM, Arnoult D, Wang C, Neutzner A, Tjandra N, Youle RJ. 2011. Bcl-x(L) retrotranslocates Bax from the mitochondria into the cytosol. Cell 145: 104-116.

Engel A, Walter P. 2008. Membrane lysis during biological membrane fusion: Collateral damage by misregulated fusion machines. J Cell Biol 183: 181-186.

Eskes R, Desagher S, Antonsson B, Martinou JC. 2000. Bid induces the oligomerization and insertion of Bax into the outer mitochondrial membrane. Mol Cell Biol 20: 929935.

Gallenne T, Gautier F, Oliver L, Hervouet E, Noel B, Hickman JA, Geneste O, Cartron PF, Vallette FM, Manon S, et al. 2009. Bax activation by the BH3-only protein Puma 
promotes cell dependence on antiapoptotic Bcl-2 family members. J Cell Biol 185: 279-290.

Garcia-Saez AJ, Chiantia S, Salgado J, Schwille P. 2007. Pore formation by a Bax-derived peptide: Effect on the line tension of the membrane probed by AFM. Biophys J 93: $103-112$.

Gavathiotis E, Suzuki M, Davis ML, Pitter K, Bird GH, Katz SG, Tu HC, Kim H, Cheng EH, Tjandra N, et al. 2008. BAX activation is initiated at a novel interaction site. Nature 455: 1076-1081.

Gavathiotis E, Reyna DE, Davis ML, Bird GH, Walensky LD. 2010. BH3-triggered structural reorganization drives the activation of proapoptotic BAX. Mol Cell 40: 481-492.

George NM, Evans JJ, Luo X. 2007. A three-helix homooligomerization domain containing $\mathrm{BH} 3$ and $\mathrm{BH} 1$ is responsible for the apoptotic activity of Bax. Genes Dev 21: 1937-1948.

Hsu YT, Youle RJ. 1997. Nonionic detergents induce dimerization among members of the Bcl-2 family. J Biol Chem 272: $13829-13834$.

Hsu YT, Wolter KG, Youle RJ. 1997. Cytosol-to-membrane redistribution of $\mathrm{Bax}$ and $\mathrm{Bcl}-\mathrm{X}(\mathrm{L})$ during apoptosis. Proc Natl Acad Sci 94: 3668-3672.

Karbowski M, Lee YJ, Gaume B, Jeong SY, Frank S, Nechushtan A, Santel A, Fuller M, Smith CL, Youle RJ. 2002. Spatial and temporal association of Bax with mitochondrial fission sites, Drp1, and Mfn2 during apoptosis. J Cell Biol 159: 931-938.

Kim H, Rafiuddin-Shah M, Tu HC, Jeffers JR, Zambetti GP, Hsieh JJ, Cheng EH. 2006. Hierarchical regulation of mitochondrion-dependent apoptosis by BCL-2 subfamilies. Nat Cell Biol 8: 1348-1358.

Kim H, Tu HC, Ren D, Takeuchi O, Jeffers JR, Zambetti GP Hsieh JJ, Cheng EH. 2009. Stepwise activation of BAX and BAK by tBID, BIM, and PUMA initiates mitochondrial apoptosis. Mol Cell 36: 487-499.

Kuwana T, Mackey MR, Perkins G, Ellisman MH, Latterich M, Schneiter R, Green DR, Newmeyer DD. 2002. Bid, Bax, and lipids cooperate to form supramolecular openings in the outer mitochondrial membrane. Cell 111: 331-342.

Kuwana T, Bouchier-Hayes L, Chipuk JE, Bonzon C, Sullivan BA, Green DR, Newmeyer DD. 2005. BH3 domains of BH3-only proteins differentially regulate Bax-mediated mitochondrial membrane permeabilization both directly and indirectly. Mol Cell 17: 525-535.

Leber B, Lin J, Andrews DW. 2007. Embedded together: The life and death consequences of interaction of the Bcl-2 family with membranes. Apoptosis 12: 897-911.

Leber B, Lin J, Andrews DW. 2010. Still embedded together binding to membranes regulates $\mathrm{Bcl}-2$ protein interactions. Oncogene 29: 5221-5230.

Letai A, Bassik MC, Walensky LD, Sorcinelli MD, Weiler S, Korsmeyer SJ. 2002. Distinct BH3 domains either sensitize or activate mitochondrial apoptosis, serving as prototype cancer therapeutics. Cancer Cell 2: 183-192.

Lin MT, Beal MF. 2006. Mitochondrial dysfunction and oxidative stress in neurodegenerative diseases. Nature 443: 787-795.
Lindsay J, Esposti MD, Gilmore AP. 2011. Bcl-2 proteins and mitochondria-Specificity in membrane targeting for death. Biochim Biophys Acta 1813: 532-529.

Llambi F, Green DR. 2011. Apoptosis and oncogenesis: Give and take in the BCL-2 family. Curr Opin Genet Dev 21: $12-20$.

Llambi F, Moldoveanu T, Tait SW, Bouchier-Hayes L, Temirov J, McCormick LL, Dillon CP, Green DR. 2011. A unified model of mammalian BCL-2 protein family interactions at the mitochondria. Mol Cell 44: 517-531.

Lovell JF, Billen LP, Bindner S, Shamas-Din A, Fradin C, Leber B, Andrews DW. 2008. Membrane binding by tBid initiates an ordered series of events culminating in membrane permeabilization by Bax. Cell 135: $1074-$ 1084.

Lucken-Ardjomande S, Montessuit S, Martinou JC. 2008a. Bax activation and stress-induced apoptosis delayed by the accumulation of cholesterol in mitochondrial membranes. Cell Death Differ 15: 484-493.

Lucken-Ardjomande S, Montessuit S, Martinou JC. 2008b. Contributions to Bax insertion and oligomerization of lipids of the mitochondrial outer membrane. Cell Death Differ 15: 929-937.

Lutter M, Fang M, Luo X, Nishijima M, Xie X, Wang X. 2000. Cardiolipin provides specificity for targeting of tBid to mitochondria. Nat Cell Biol 2: 754-761.

Lutter M, Perkins GA, Wang X. 2001. The pro-apoptotic Bcl-2 family member tBid localizes to mitochondrial contact sites. BMC Cell Biol 2: 22.

Martinez-Caballero S, Dejean LM, Kinnally MS, Oh KJ, Mannella CA, Kinnally KW. 2009. Assembly of the mitochondrial apoptosis-induced channel, MAC. J Biol Chem 284: 12235-12245.

Martinou JC, Youle RJ. 2011. Mitochondria in apoptosis: Bcl-2 family members and mitochondrial dynamics. Dev Cell 21: 92-101.

Moldoveanu T, Liu Q, Tocilj A, Watson M, Shore G, Gehring K. 2006. The X-ray structure of a BAK homodimer reveals an inhibitory zinc binding site. Mol Cell 24: 677-688.

Montessuit S, Somasekharan SP, Terrones O, Lucken-Ardjomande S, Herzig S, Schwarzenbacher R, Manstein DJ, Bossy-Wetzel E, Basanez G, Meda P, et al. 2010. Membrane remodeling induced by the dynamin-related protein Drp1 stimulates Bax oligomerization. Cell 142: 889-901.

Muchmore SW, Sattler M, Liang H, Meadows RP, Harlan JE, Yoon HS, Nettesheim D, Chang BS, Thompson CB, Wong SL, et al. 1996. X-ray and NMR structure of human Bcl-xL, an inhibitor of programmed cell death. Nature 381: 335-341.

Nakagawa T, Shimizu S, Watanabe T, Yamaguchi O, Otsu K, Yamagata H, Inohara H, Kubo T, Tsujimoto Y. 2005 . Cyclophilin D-dependent mitochondrial permeability transition regulates some necrotic but not apoptotic cell death. Nature 434: 652-658.

Ni Chonghaile T, Sarosiek KA, Vo TT, Ryan JA, Tammareddi A, Moore Vdel G, Deng J, Anderson KC, Richardson P, Tai YT, et al. 2011. Pretreatment mitochondrial priming correlates with clinical response to cytotoxic chemotherapy. Science 334: 1129-1133. 
Oh KJ, Singh P, Lee K, Foss K, Lee S, Park M, Aluvila S, Kim RS, Symersky J, Walters DE. 2010. Conformational changes in BAK, a pore-forming proapoptotic $\mathrm{Bcl}-2 \mathrm{fam}-$ ily member, upon membrane insertion and direct evidence for the existence of $\mathrm{BH} 3-\mathrm{BH} 3$ contact interface in BAK homo-oligomers. J Biol Chem 285: 28924-28937.

Ott M, Norberg E, Zhivotovsky B, Orrenius S. 2009. Mitochondrial targeting of tBid/Bax: A role for the TOM complex? Cell Death Differ 16: 1075-1082.

Petros AM, Nettesheim DG, Wang Y, Olejniczak ET, Meadows RP, Mack J, Swift K, Matayoshi ED, Zhang H, Thompson CB, et al. 2000. Rationale for Bcl-xL/Bad peptide complex formation from structure, mutagenesis, and biophysical studies. Protein Sci 9: 2528-2534.

Qian S, Wang W, Yang L, Huang HW. 2008. Structure of transmembrane pore induced by Bax-derived peptide: Evidence for lipidic pores. Proc Natl Acad Sci 105: 17379-17383.

Rehm M, Dussmann H, Prehn JH. 2003. Real-time single cell analysis of Smac/DIABLO release during apoptosis. J Cell Biol 162: 1031-1043.

Ren D, Tu HC, Kim H, Wang GX, Bean GR, Takeuchi O, Jeffers JR, Zambetti GP, Hsieh JJ, Cheng EH. 2010. BID, BIM, and PUMA are essential for activation of the BAXand BAK-dependent cell death program. Science 330: 1390-1393.

Satsoura D, Kucerka N, Shivakumar S, Pencer J, Griffiths C, Leber B, Andrews DW, Katsaras J, Fradin C. 2012. Interaction of the full-length Bax protein with biomimetic mitochondrial liposomes: A small-angle neutron scattering and fluorescence study. Biochim Biophys Acta 1818: 384-401.

Sattler M, Liang H, Nettesheim D, Meadows RP, Harlan JE, Eberstadt M, Yoon HS, Shuker SB, Chang BS, Minn AJ, et al. 1997. Structure of Bcl-xL-Bak peptide complex: Recognition between regulators of apoptosis. Science 275: 983-986.

Schafer B, Quispe J, Choudhary V, Chipuk JE, Ajero TG, Du H, Schneiter R, Kuwana T. 2009. Mitochondrial outer membrane proteins assist Bid in Bax-mediated lipidic pore formation. Mol Biol Cell 20: 2276-2285.

Schlesinger PH, Gross A, Yin XM, Yamamoto K, Saito M, Waksman G, Korsmeyer SJ. 1997. Comparison of the ion channel characteristics of proapoptotic BAX and antiapoptotic BCL-2. Proc Natl Acad Sci 94: 11357-11362.

Suzuki M, Youle RJ, Tjandra N. 2000. Structure of Bax: Coregulation of dimer formation and intracellular localization. Cell 103: 645-654.
Tan C, Dlugosz PJ, Peng J, Zhang Z, Lapolla SM, Plafker SM, Andrews DW, Lin J. 2006. Auto-activation of the apoptosis protein Bax increases mitochondrial membrane permeability and is inhibited by Bcl-2. J Biol Chem 281: 14764-14775.

Taylor RC, Cullen SP, Martin SJ. 2008. Apoptosis: Controlled demolition at the cellular level. Nat Rev Mol Cell Biol 9: 231-241.

Terradillos O, Montessuit S, Huang DC, Martinou JC. 2002. Direct addition of BimL to mitochondria does not lead to cytochrome $c$ release. FEBS Lett 522: 29-34.

Terrones O, Antonsson B, Yamaguchi H, Wang HG, Liu J, Lee RM, Herrmann A, Basanez G. 2004. Lipidic pore formation by the concerted action of proapoptotic BAX and tBID. J Biol Chem 279: 30081-30091.

Vogler M, Weber K, Dinsdale D, Schmitz I, SchulzeOsthoff K, Dyer MJS, Cohen GM. 2009. Different forms of cell death induced by putative BCL-2 inhibitors. Cell Death Differ 16: 1030-1039.

Walensky LD, Pitter K, Morash J, Oh KJ, Barbuto S, Fisher J, Smith E, Verdine GL, Korsmeyer SJ. 2006. A stapled BID BH3 helix directly binds and activates BAX. Mol Cell 24: 199-210.

Wei MC, Zong WX, Cheng EH, Lindsten T, Panoutsakopoulou V, Ross AJ, Roth KA, MacGregor GR, Thompson CB, Korsmeyer SJ. 2001. Proapoptotic BAX and BAK: A requisite gateway to mitochondrial dysfunction and death. Science 292: 727-730.

Willis SN, Chen L, Dewson G, Wei A, Naik E, Fletcher JI, Adams JM, Huang DC. 2005. Proapoptotic Bak is sequestered by Mcl-1 and Bcl-xL, but not Bcl-2, until displaced by BH3-only proteins. Genes Dev 19: 1294-1305.

Willis SN, Fletcher JI, Kaufmann T, van Delft MF, Chen L, Czabotar PE, Ierino H, Lee EF, Fairlie WD, Bouillet P, et al. 2007. Apoptosis initiated when BH3 ligands engage multiple Bcl-2 homologs, not Bax or Bak. Science 315: 856-859.

Youle RJ, Strasser A. 2008. The BCL-2 protein family: Opposing activities that mediate cell death. Nat Rev Mol Cell Biol 9: 47-59.

Zaltsman Y, Shachnai L, Yivgi-Ohana N, Schwarz M, Maryanovich M, Houtkooper RH, Vaz FM, De Leonardis F Fiermonte G, Palmieri F, et al. 2010. MTCH2/MIMP is a major facilitator of tBID recruitment to mitochondria. Nat Cell Biol 12: 553-562.

Zhang Z, Zhu W, Lapolla SM, Miao Y, Shao Y, Falcone M, Boreham D, McFarlane N, Ding J, Johnson AE, et al. 2010. Bax forms an oligomer via separate, yet interdependent, surfaces. J Biol Chem 285: 17614-17627. 


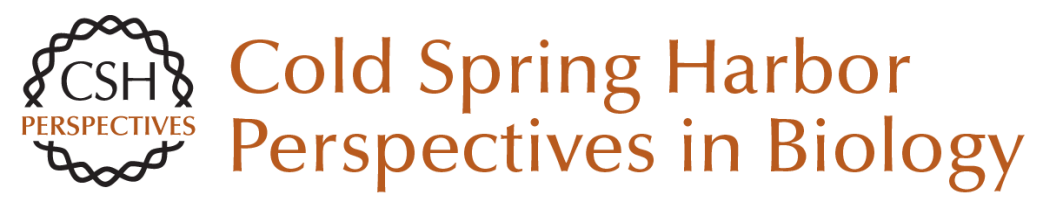

\section{Where Killers Meet--Permeabilization of the Outer Mitochondrial Membrane during Apoptosis}

Tom Bender and Jean-Claude Martinou

Cold Spring Harb Perspect Biol 2013; doi: 10.1101/cshperspect.a011106

Subject Collection Mitochondria

Altered Sulfide $\left(\mathrm{H}_{2} \mathrm{~S}\right)$ Metabolism in Ethylmalonic Encephalopathy

Valeria Tiranti and Massimo Zeviani

Mitochondrial DNA Genetics and the

Heteroplasmy Conundrum in Evolution and

Disease

Douglas C. Wallace and Dimitra Chalkia

The Role of Mitochondria in Cellular Iron-Sulfur

Protein Biogenesis: Mechanisms, Connected

Processes, and Diseases

Oliver Stehling and Roland Lill

Mechanisms of Mitochondrial Fission and Fusion Alexander M. van der Bliek, Qinfang Shen and Sumihiro Kawajiri

The Mitochondrial Nucleoid: Integrating Mitochondrial DNA into Cellular Homeostasis

Robert Gilkerson, Liliana Bravo, Iraselia Garcia, et al.

Relevance of Mitochondrial Genetics and

Metabolism in Cancer Development

Giuseppe Gasparre, Anna Maria Porcelli, Giorgio

Lenaz, et al.

Mitochondrial Quality Control Mediated by PINK1 and Parkin: Links to Parkinsonism

Derek Narendra, John E. Walker and Richard Youle
Where Killers Meet--Permeabilization of the Outer

Mitochondrial Membrane during Apoptosis

Tom Bender and Jean-Claude Martinou

Mitochondrial Biogenesis through Activation of

Nuclear Signaling Proteins John E. Dominy and Pere Puigserver

Mitochondrial Trafficking in Neurons Thomas L. Schwarz

Mitochondrial Dysfunction and Defective Autophagy in the Pathogenesis of Collagen VI Muscular Dystrophies

Paolo Bernardi and Paolo Bonaldo

Clinical and Molecular Features of POLG-Related Mitochondrial Disease

Jeffrey D. Stumpf, Russell P. Saneto and William C. Copeland

Mitochondrial Metabolism, Sirtuins, and Aging Michael N. Sack and Toren Finkel

Mechanisms of Protein Sorting in Mitochondria Diana Stojanovski, Maria Bohnert, Nikolaus Pfanner, et al.

For additional articles in this collection, see http://cshperspectives.cshlp.org/cgi/collection/

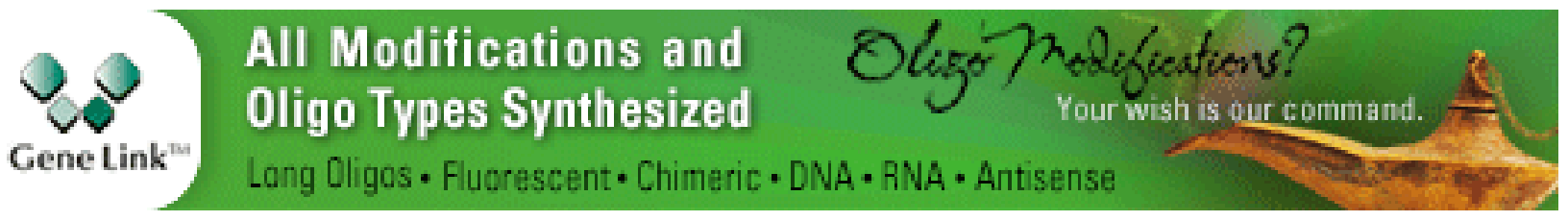




\section{Mitochondrial Evolution}

Michael W. Gray

For additional articles in this collection, see http://cshperspectives.cshlp.org/cgi/collection/

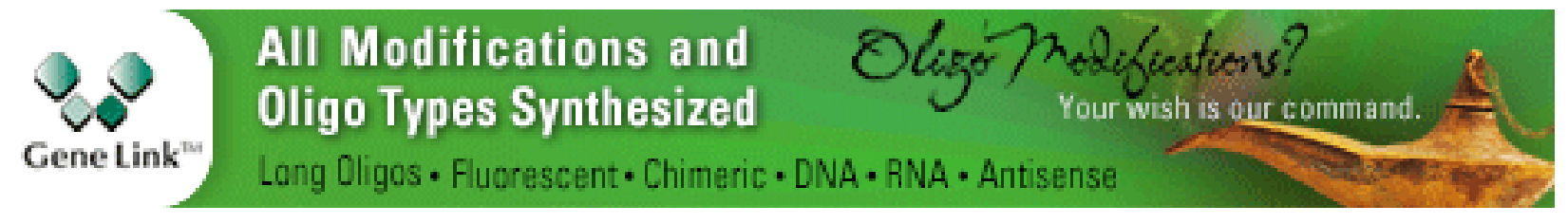

Copyright @ 2013 Cold Spring Harbor Laboratory Press; all rights reserved 